\title{
NUTRACEUTICALS IN DYSLIPIDEMIA: AN ALTERNATIVE APPROACH
}

\author{
SAURABH AGARWAL, SEREEN R THOMSON, SHIVAPRAKASH G*
}

Department of Pharmacology, Kasturba Medical College, Manipal University, Manipal, Karnataka, India. Email: sivag1977@gmail.com

\author{
Received: 24 September 2016, Revised and Accepted: 06 October 2016
}

\section{ABSTRACT}

Dyslipidemia is a well-known modifiable risk factor for preventing cardiovascular diseases. The present therapy mainly aiming at pharmacological treatment to reduce lipid levels may not be effective in each individual to meet the target levels. Diet and lifestyle modification has an important role in treating such chronic illnesses. Nutraceuticals, which are derived from food products, provide one such alternate therapy for the management of dyslipidemia. Some of them have proven to be effective for treating dyslipidemia while others require further studies. Much work is still required to understand the pharmacokinetics and mechanism of action of these products. Nutraceuticals hold promise in the clinical management of dyslipidemia and can be used as primary preventive therapy as more evidence from studies comes in light.

Keywords: Dyslipidemia, Nutraceuticals, Cardiovascular disease, Statins.

(C) 2017 The Authors. Published by Innovare Academic Sciences Pvt Ltd. This is an open access article under the CC BY license (http://creativecommons org/licenses/by/4. 0/) DOI: http://dx.doi.org/10.22159/ajpcr.2017.v10i1.15360

\section{INTRODUCTION}

Globally, cardiovascular disease (CVD) is still the major cause of death which accounts for nearly 17.3 million deaths per year, and this is further estimated to grow to nearly 23.6 million by 2030. In 2008, 30\% of all deaths globally was due to cardiovascular causes with nearly $80 \%$ of these deaths taking place in low- and middle-income regions [1]. Lipid disorders induce vascular damage by inflammation, oxidative stress, and immune dysregulation which, in turn, can accelerate the process of atherosclerosis and can further increase the risk of CVDs [2] Dyslipidemia is a proven modifiable risk factor for CVDs, and its treatment has an important role in preventing these diseases [3-5].

In a meta-analysis done in 2010, it was estimated that by reducing 1.0 $\mathrm{mmol} / \mathrm{L}(38.7 \mathrm{mg} / \mathrm{dL}$ ) of low-density lipoprotein-cholesterol (LDL-C), there was a corresponding $22 \%$ decrease in morbidity and mortality due to CVDs [3]. Although pharmacological therapy for dyslipidemia such as statins is well-established treatment option, nutritional, and lifestyle modification are important in reducing the risk of CVD. It is estimated that lifestyle changes and diet can reduce CVD risk by $82 \%$ [6], whereas nutritional practices themselves can reduce the risk by $60 \%$ [7]. Prolonged pharmacological therapy leads to intolerable adverse effects such as myopathy, rhabdomyolysis, raised liver enzymes, neuropathy, glucose intolerance, or gastrointestinal disturbances [8].

Thus, safer alternatives are necessary to treat dyslipidemia. Nutraceuticals are one such approach which can help reduce lipid levels. Apart from their role in dyslipidemia and cardioprotective action, nutraceuticals have also been found to have antimicrobial, antidiabetic, anti-inflammatory, antineoplastic, hepatoprotective, and neuroprotective action as well $[9,10]$.

These products can act as an alternate to conventional pharmacological therapy or adjuvant to them. This review will be focused on nutraceutical products and their lipid-lowering effect, some of which are proven to control dyslipidemia while others still need more studies to establish their role.

\section{NUTRACEUTICALS: DEFINITION AND CLASSIFICATION}

The term nutraceutical was coined from nutrition and pharmaceutical by Stephen Defelice in 1989. He defined nutraceuticals as "any substance that is a food or a part of a food and provides medical or health benefits, including the prevention and treatment of disease" $[11,12]$. Recently, the Food Safety and Standards Authority of India in August 2015 has defined nutraceutical as "a naturally occurring chemical compound having a physiological benefit or provide protection against chronic disease, isolated and purified from food or nonfood source and may be prepared and marketed in the food format of granules, powder, tablet, capsule, liquid, or gel and may be packed in sachet, ampoule, bottle, etc., and to be taken as measured unit quantities" [13].

Nutraceuticals are classified into two categories: Traditional and nontraditional by Singh and Sinha (2012). The traditional category includes all the substances naturally contained in foods, not changed by biotechnological techniques, industrial improvements, and/or de novo synthesis. The nontraditional nutraceuticals are externally added to the foods by bioengineering actions. The two categories are further divided into subgroups (Fig. 1).

The traditional category is divided into:

1. Chemical constituents: Herbal and phytochemical products

2. Probiotic microorganisms: Symbiotic bacteria which promote digestion and absorption of nutrients

3. Nutraceutical enzymes: Derived from microbial, plant, or animal sources.

The nontraditional category is divided into:

1. Fortified nutraceuticals: These are agricultural and natural food with artificially added nutrients

2. Recombinant nutraceuticals: Energy providing food produced with the help of biotechnology and genetic engineering technology.

\section{NUTRACEUTICALS FOR DYSLIPIDEMIA}

Nutraceuticals can effectively reduce the problem of dyslipidemia, atherosclerosis, and coronary heart disease (CHD) development as already validated in the various studies [14-17]. Nutraceuticals can act on several biochemical pathways able to influence lipid disorders in the human body. Apart from the lipid-lowering effect, many nutraceuticals have antioxidant, antiplatelet, and anti-inflammatory properties which further enhances their beneficial role [17-19].

\section{Resveratrol}

Resveratrol is a phytoalexin produced by more than 70 different plants. Its major concentrations are found in grape, berries, peanuts, 


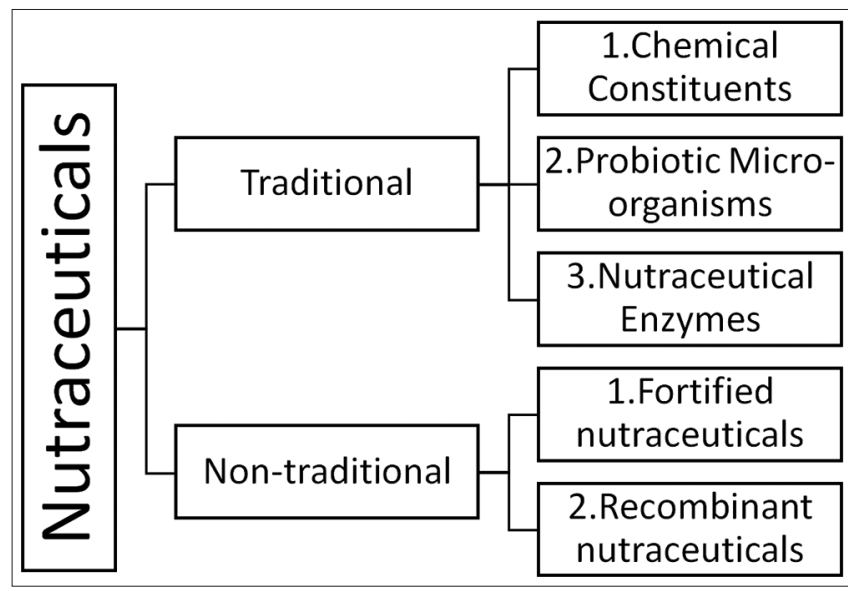

Fig. 1: Nutraceuticals classification

and red wine [20]. In 1940, resveratrol was first identified as the medicinal component of grapes. It was extracted from the dried roots of Polygonum cuspidatum (also known as Ko-jo-kon in Japan) and used in the treatment of dyslipidemia [21]. Multiple lipid-lowering mechanisms have been proposed for resveratrol such as:

a. It is similar to statin therapy which acts by inhibiting hydroxymethylglutaryl coenzyme A (HMG-CoA) reductase and by increasing the ratio of apolipoprotein $\mathrm{A} 1$ (apo-A1) with respect to apo-B [22]

b. It also promotes reverse cholesterol transport by increasing highdensity lipoprotein (HDL) levels, which is crucial in removing cholesterol from the body [23].

c. Adipocytes which store cholesterol promote atherogenesis while resveratrol prevents adipogenesis by inducing apoptosis of fat cells by silent mating type information regulation 1 homolog and tumor necrosis factor (TNF) related apoptosis inducing ligand [24].

d. A study done by Chen et al. hypothesized that the lipid-lowering effect of resveratrol is due to its activity on cholesterol $7 \alpha$-hydroxylase. It mediates the conversion of cholesterol in $7 \alpha$-hydroxycholesterol and, subsequently, in cholic acid. Bile acids genesis contributes to the elimination of cholesterol from plasma [25].

Apart from the lipid-lowering activity, it also has various other beneficial effects such as antioxidant, anti-inflammatory, and antiplatelet.

a. Resveratrol does not show any direct scavenging activity of reactive oxygen free radical; instead, it upregulates the inbuilt cellular antioxidant system which is credited for its protective effects against oxidative injury [26].

b. The anti-inflammatory activity of resveratrol has been shown by inhibiting cyclooxygenase (COX), which mediates conversion of arachidonic acid (AA) into thromboxane A2 (TxA2), prostaglandins (PGs), and prostacyclins [27,28].

c. Resveratrol also demonstrates its antiplatelet activity by inhibiting TxA2 formation by inhibiting COX enzyme. In addition, resveratrol inhibits activation of platelets by decreasing the intracellular calcium levels $\left(\left[\mathrm{Ca}^{2+}\right]_{\mathrm{i}}\right)$ of the platelet. This plays a key role in platelet aggregation activity [29].

Although resveratrol is considered as a food supplement for its free radical scavenging activity and promoting health, it has still not reached the stage for clinical use. Resveratrol has a half-life of 8-14 minutes and has been shown to be extensively metabolized in the body. The recommended dosage of resveratrol is $250 \mathrm{mg}$ /day [30]. Many clinical trials are currently in progress to investigate the beneficial effect and safety profile [31].

\section{Soy derivatives}

Soybeans contain substances known as soy protein and isoflavones which help in decreasing the risk of CVD. Daidzin, genistein, and glycitin are the major isoflavones and are similar in structure to $17-\beta$ estradiol [32]. These isoflavones attach to estrogen A and B receptors and act as a partial estrogen agonist. Among different trails consumption of soy proteins reduced lipid levels both in animals and humans, though the level of reduction was different in various studies [16]. Soy reduces the absorption and micellar content of lipids by fiber, isoflavones, and phytoestrogens [33]. Soy proteins increase LDL-receptor (LDL-R) expression in human beings [34]. With 30-50 g soy/day, total cholesterol (TC), LDL-C, and triglycerides (TGs) decreased by 2-9.3, 4-12.9, and $10.5 \%$, respectively, with $2.4 \%$ increase in HDL-cholesterol (HDL-C) $[35,36]$. A meta-analysis of 29 controlled trials showed that an average soy protein consumption of $47 \mathrm{~g} /$ day decreased TC levels by $9 \%$, LDL-C by $12.9 \%$, and TGs by $10.5 \%$ with an insignificant effect on HDL-C [37]. In 1999, health benefits of soy protein in the reduction of CHD due to its cholesterol-lowering effect have been approved by the US Food and Drug Administration (FDA) [38].

With recent advances in proteomics, the mechanism of action has become clearer. This is helpful in selecting the most appropriate form of soy protein for the treatment of dyslipidemia. Soybean contains mainly 2 storage proteins $7 \mathrm{~S}$ and $11 \mathrm{~S}$ globulins. It was noted that the hypocholesterolemic effect of soy protein is mainly due to $7 \mathrm{~S}$ globulin while $11 \mathrm{~S}$ is the inactive component. The $7 \mathrm{~S}$ unit is mainly involved in upregulation of LDL-R $[39,40]$. The effectiveness of soy protein as proven in various studies reinforces the recommendation to increase soy protein in the diet for cardiovascular protection.

\section{Omega-3 fatty acids (FAs)}

Long chain omega-3 FA including eicosapentaenoic acid (EPA) and docosahexaenoic acid (DHA) are the main components found in fish oil. Fish oil can be safely employed in dyslipidemia treatment and has been shown to prevent both primary and secondary CVDs in various trials. Large-scale epidemiological studies advocate that individuals at risk for CHD benefits from the intake of omega-3 FAs, although the ideal intake presently is unclear $[41,42]$. The proposed mechanism for this effect seems to be due to reduction in TGs levels, antiarrhythmic effects, decreased platelet aggregation, plaque stabilization, reduced blood pressure, and a decrease in heart rate [42]. Omega-3 polyunsaturated FAs (PUFAs) by altering eicosanoid biosynthesis affects signaling, changes membrane fluidity which further affects enzymatic reactions and binding to a receptor. It directly activates factors controlling transcription factor which regulate genes affecting hyperlipidemia and inflammation. The mechanism of action for the hypotriglyceridemic effect has been identified as upregulation of peroxisome proliferator activated receptor $\alpha$ (PPAR- $\alpha$ ) in dyslipidemic patients. The administration of these compounds enhance catabolism of very LDL (VLDL) by lipoprotein lipase (LPL) and reduce production of VLDL by repressing apo CIII and apo B expression. Such an action enhances the hypotriglyceridemic effects of these compounds. Apo CII (a regulator of LPL activation) expression was downregulated in $\mathrm{n}-3$ PUFA supplemented patients. Therefore, triacylglycerols clearance was improved in treated patients [43]. GISSI prevention study demonstrated that omega-3 PUFA supplements lowered mortality, sudden cardiac death, and overall cardiovascular deaths by $20 \%, 45 \%$, and 20\%, respectively [44]. According to Japan EPA Lipid Intervention Study, when statin was combined with $1.8 \mathrm{~g}$ of omega- 3 FAs results obtained showed an additional risk reduction in major coronary events and in myocardial infarction (MI) by $19 \%$, and a reduction of $20 \%$ in cerebrovascular events [45]. The diet and reinfarction trial showed 29\% reduction in death in post-MI men, whereas Kuppio Heart Study reported 44\% reduction in CHD [45]. Omega-3 FAs decrease progression of CHD, prevent restenosis of coronary artery stent, and help in plaque stabilization [45]. "Omega-3 index" as proposed by Harris and Von schacky, is considered as a risk factor for CHD s and is defined as "EPA + DHA as a percentage of total red blood cell FA." A value of $8 \%$ or above is considered cardioprotective, whereas values below $4 \%$ are considered to be related with the increase in the risk of CHD [46]. Apart from lipid-lowering effect, omega-3 FA has an anti-inflammatory and antiplatelet role also. In human diet, the ratio of AA to EPA and DHA is important. Fish oil increases EPA in membrane and EPA/AA 
ratio leading to dampened prostanoid signaling. It mainly acts on COX1 mediating the production of PG D, E, and F. Platelets convert EPA to TxA3 via COX-1 [47]. EPA increases production of prostacyclin, which is platelet antiaggregatory. Increased EPA/AA ratio enhances PGE3 production from EPA using COX-2 [48].

\section{Berberine}

Berberine is a highly concentrated natural isoquinoline alkaloid found in numerous medicinal plants (Hydrastis canadensis, Coptis chinensis, Berberis aquifolium, Berberis vulgaris, Berberis aristata). It is bitter in taste and has bright yellow. It is found in the bark, roots, stems, and rhizome of these plants. It has been used traditionally for its antimicrobial and antisecretory properties [49]. The substance is metabolized by the liver and excreted primarily via the bile after glucuronidation. The target organ is mainly the liver, however, mechanism of action is complex and not fully clear. Berberine probably inhibits the transcription of the mRNA encoding the proprotein convertase subtilisin/kexina type 9 (PCSK9). It is the protein that facilitates the separation of hepatic LDL-R from the cell surface toward the lysosomes where it is usually degraded with a resulting prolongation of the receptor's half-life [50]. This results in an increased expression of the LDL-R. Increased LDL-R can then recapture more LDL-C from the bloodstream to be sent for excretion via the bile [51]. Berberine may also decrease plasma lipids which inhibit cholesterol and TG synthesis by activation of adenosine monophosphate-activated protein kinase, which further inhibits HMG-CoA reductase [52]. In a study, it was seen that berberine decreased TC levels by $29 \%$, TGs levels by $35 \%$, and LDL-C by $25 \%$, whereas HDL-C levels remained unchanged [50]. When data from 11 randomized controlled trails was analyzed involving 874 patients with dyslipidemia, Type 2 diabetes mellitus (DM) or with both conditions and given berberine ranging from $0.5 \mathrm{~g}$ to $1.5 \mathrm{~g} /$ day, it showed a significant difference between the berberine and the control groups. A reduction in TC, LDL-C, and TGs of $23.5 \mathrm{mg} / \mathrm{dL}, 25.1 \mathrm{mg} / \mathrm{dL}$, and $43.8 \mathrm{mg} / \mathrm{dL}$, respectively, was noted while HDL-C was significantly increased by $1.93 \mathrm{mg} / \mathrm{dL}$ [53]. Some adverse effects of berberine have also been noted such as diarrhea, constipation, bloating sensation, and bitter taste in the mouth [53]. In another study, the hypoglycemic activity of berberine was demonstrated in Type $2 \mathrm{DM}$. This action is proposed to be by improving the resistance to insulin and by increasing the expression of insulin receptors [54]. Berberine is one of the most interesting nutraceuticals available because of its action on PCSK9 and its ability to act on other lipid-lowering pathways as well.

\section{Red yeast rice (RYR)}

RYR is a fermented product of rice. Chinese have been using it for centuries to make wine from rice, to enhance flavor, as a coloring agent, for food and to promote circulation and digestion [55]. In the year 1895 yeast Monascus purpureus was obtained from RYR [56]. In 1979, endo found a compound produced by this yeast and called it monacolin $\mathrm{K}$ which inhibited cholesterol synthesis by a mechanism of action similar to statins [57]. There are several kinds of monacolins; they have a complex molecular structure which is very similar to that of natural statins, in particular to lovastatin. Their metabolism is similar to that of the fat-soluble statins, which are quite easily absorbed by the intestine as well as metabolized by the isoform 3A4 cytochrome P450 [58]. Clinical studies showed that effect on plasma lipid levels was dose dependent, with total cholesterol levels reduction of 16-31\%, LDL-C reduction of $22-32 \%$, TGs reduction of $0-36 \%$, and variable changes in HDL-C levels, with an increase up to 20\% [59]. The China Coronary Secondary Prevention Study investigated RYR for its role in decreasing the risk of cardiovascular events. The trial enrolled a total 4870 patients who had a history of acute MI and increased cholesterol levels. Patients randomized to the test group received Xuezhikang (partially purified extract of RYR), and the other group received placebo for a duration of 4.5 years. Results showed that the group treated with RYR showed a reduction in total mortality by $33 \%$, deaths due to cardiovascular events by $30 \%$, and the requirement of coronary reperfusion by $33 \%$ [59] Another study evaluated the safety and efficacy of RYR in patients with statin-associated myalgias. In the RYR group $(1800 \mathrm{mg} /$ day, equivalent to lovastatin $6 \mathrm{mg}$ ), LDL-C reduced by $35 \mathrm{mg} / \mathrm{dl}$ [60]. A trial between RYR given $2400 \mathrm{mg}$ twice daily and pravastatin given $20 \mathrm{mg}$ twice daily showed good tolerance and reasonably good LDL-C decreasing effect (30\% and 27\%, respectively) [61]. FDA, in 2001, said that Cholestin (which is a product of RYR) should not be considered as a dietary supplement but instead as a drug because it contains lovastatin and was associated with statin-related adverse effects [62]. RYR has shown good efficacy as lipid-lowering product and can be a good alternative to statin intolerant patients.

\section{Curcumin}

It is the bioactive compound of turmeric (Curcuma longa). Curcumin exhibits anticarcinogenic, anti-inflammatory, antioxidative, antiinfectious, lipid-lowering, and blood glucose-lowering activity. It also blocks activities of TNF, vascular endothelial growth factor, and epithelial growth factor [63]. The hypolipidemic effects of curcumin are due to: Increase in the LDL-R; increase in enzyme farnesyl diphosphate synthase and HMG-CoA reductase; promote sterol regulatory element-binding proteins genes; downregulates PPAR [64]. It enhances the activity of cholesterol- $7 \alpha$-hydroxylase, which increases the rate of cholesterol breakdown and also increases the hepatic superoxide dismutase and glutathione peroxidase leading to decrease in oxidation of LDL-C. Curcumin can aggravate bleeding in patients who are on anticoagulants. Curcumin also has a protective effect from hyperlipidemia induced by alcohol and PUFA. A significant reduction in serum levels of lipid peroxides by $33 \%$, decrease in total cholesterol by $11.6 \%$, and an increase in HDL-C by $29 \%$ [65]. Consumption of about $500 \mathrm{mg}$ /day of good quality curcumin is recommended for the patients.

\section{NUTRACEUTICALS VERSUS LIPID-LOWERING AGENTS}

At present, statins are considered as the main first-line treatment for dyslipidemia in most hypercholesterolemic patients. It has also been proven in various studies that nutraceuticals reduce dyslipidemia burden. This action is important when considering patients who are intolerant to statins and suffering from severe lipid disorders or whose statin treatment is not able to control dyslipidemia and reach the desired results. Nutraceuticals could be safely used in these individuals to control dyslipidemia and reduce the cardiovascular risk. The reasons for recent interest in nutraceuticals as an alternate dyslipidemic therapy are mainly due to:

a. Medical treatment cost is increasing around the world

b. Consumers want better preventive therapies for chronic diseases

c. Interest in alternative medical and natural cures

d. Technical advances in the food industry leading development of health promoting foods

e. Patients want treatment with less/no side effects compared to pharmacological drugs.

In light of the present evidence, it can be said that some nutraceuticals can be used as a replacement therapy in the patients who are intolerant to the pharmacological therapy while others still need more evidence and studies to ascertain their role in lipid-lowering therapy.

\section{FUTURE DIRECTIONS FOR NUTRACEUTICALS}

The early 1980s marked the beginning of the revolution of nutraceuticals when physicians began to educate their colleagues and consumers about these substances due to the various clinical studies done in this regard. Japan invented the present concept of nutraceuticals in the early 1980s. During the same period, the Japanese health agency to control the rising health-care cost, especially due to the rising elderly population recognized the need to improve the quality of life and also to increase the life expectancy of the elderly population. This lead to the development of food products called Foods for Specified Health Use mainly to reduce the risk of a disease and promotion of health. Presently, consumer interest for health and diet has increased around the world because of the recognition of the fact that risk of disease can be reduced and one can maintain disease free health with no adverse effects through adopting a healthy lifestyle and dietary changes. 
The market for functional food and nutraceuticals has been in existence for many years but is less recognized because it is unorganized. The future though looks bright but has many challenges such as different regulations for different countries, difficulty in claiming the health benefits due to no scientific evidence and very less innovation by food manufacturing units. Although many countries have legislation for regulating such food products, it does not necessarily result in getting permission and approval for these products, especially in countries which have a strict law for health claim approvals such as the US and Japan [66]. Moreover, the nutraceutical industry is still considered as an idea rather than reality because it does not clearly differentiate functional foods and food supplements which create confusion in minds of consumers. Few companies have now begun to understand this problem and are looking at better ways to combine both nutritional products along with medical treatment to provide a more holistic healthcare.

Globally, nutraceutical and functional food market is expected to grow from US $\$ 182.60$ billion in the year 2015 to US $\$ 278.96$ billion by the year 2021 [67]. Mainly due increase in the elderly population and strong over the counter market in various countries. Indian nutraceutical market is at a nascent stage but emerging at a fast rate. By the year 2017, the growth of nutraceutical market in India is expected to be $70.74 \%$ when compared to the dietary supplement market. There has been a rapid growth in nutraceutical market in India in past few years. The main factors which are propelling this market are increasing awareness about the availability of different types of nutraceuticals available in the market, increase in levels of health consciousness and increase in income of people who are now willing to spend on health promoting food products. The major presence of the nutraceuticals market of India is in the urban parts of the country. The busy lifestyle seen in the urban class has encouraged the increase in health consciousness and is driving the growth of this industry. The huge population base of India also gives a good opportunity for the nutraceutical market to grow in coming years. At a compound annual growth rate of $17 \%$, it is projected that the Indian nutraceutical market will grow to $\$ 4$ billion by the year 2018 [68].

\section{CONCLUSION}

Functional food and nutraceuticals have the potential to become the future of primary prevention in dyslipidemia treatment, and secondarily, in CVD prevention because of their established useful actions in past studies. The use of substances derived from nutrients for lipid-lowering purposes represents a viable alternative to commonly used pharmacological therapy. Factors such as changing lifestyle, rising awareness about health and fitness, aging population, and chronic illnesses are promoting nutraceutical use. Nutraceuticals have varied efficacy levels in modifying the lipid levels of the individual. Future studies are required to explain the exact pharmacokinetics, pharmacodynamics, and mechanism of action of nutraceuticals to better adopt these molecules for their therapeutic role in dyslipidemia treatment. Proper guidelines for dependability of industrialized processes and standardization of the foodstuffs are also needed. Escalating the scientific research process which can confirm the efficacy and safety of nutraceuticals as lipid-lowering agent can further increase the investment in the manufacturing technologies and utilization of these products. Although evidence-based medicine does not allow the use of such nutraceuticals in modern clinical practice, the use of such products has been increasing since the past few years. Once the hurdles that limit the role of nutraceuticals have been resolved, its use in various disease prevention and treatment will increase in the coming future.

\section{ACKNOWLEDGMENTS}

The authors would like to acknowledge the contribution of the Manipal University in the making of this article.

\section{REFERENCES}

1. Available from: http://www.who.int/mediacentre/factsheets/fs317/en.

2. Tian N, Penman AD, Mawson AR, Manning RD Jr, Flessner MF. Association between circulating specific leukocyte types and blood pressure: The atherosclerosis risk in communities (ARIC) study. J Am Soc Hypertens 2010;4(6):272-83.

3. Cholesterol Treatment Trialists' (CTT) Collaboration, Baigent C, Blackwell L, Emberson J, Holland LE, Reith C, et al. Efficacy and safety of more intensive lowering of LDL cholesterol: A meta-analysis of data from 170,000 participants in 26 randomised trials. Lancet 2010;376(9753):1670-81.

4. Gillespie CD, Keenan NL, Miner JB, Hong Y; Centers for Disease Control and Prevention (CDC). Screening for lipid disorders among adults - National Health and Nutrition Examination Survey, United States, 2005-2008. MMWR Suppl 2012;61(2):26-31.

5. Roger VL, Go AS, Lloyd-Jones DM, Benjamin EJ, Berry JD, Borden WB, et al. Heart disease and stroke statistics--2012 update: A report from the American Heart Association. Circulation 2012;125(1):e2-20.

6. Stampfer MJ, Hu FB, Manson JE, Rimm EB, Willett WC. Primary prevention of coronary heart disease in women through diet and lifestyle. N Engl J Med 2000;343:16-22.

7. Kris-Etherton PM, Etherton TD, Carlson J, Gardner C. Recent discoveries in inclusive food-based approaches and dietary patterns for reduction in risk for cardiovascular disease. Curr Opin Lipidol 2002;13(4):397-407.

8. Mills EJ, Wu P, Chong G, Ghement I, Singh S, Akl EA, et al. Efficacy and safety of statin treatment for cardiovascular disease: A network meta-analysis of 170,255 patients from 76 randomized trials. QJM 2011;104(2):109-24.

9. Tapas AR, Sakarkar DM, Kakde RB. Flavonoids as nutraceuticals: A review. Trop J Pharm Res 2008;7(3):1089-99.

10. Rajasekaran A, Sivagnanam G, Xavier R. Nutraceuticals as therapeutic agents: A Review. Res J Pharm Tech 2008;1:328-40.

11. DeFelice SL. The nutraceutical revolution: Its impact on food industry R\&D. Trends Food Sci Technol 1995;6(2):59-61.

12. Kalra EK. Nutraceutical - definition and introduction. AAPS PharmSci 2003;5(3):E25.

13. Available from: http://www.fssai.gov.in/Portals/0/Pdf/Draft Regulation_on_Nutraceuticals_WTO_23_07_2015.pdf.

14. Ciccone $\overline{\mathrm{MM}}$, Scicchitano $\mathrm{P}$, Gesualdo $\overline{\mathrm{M}}$, Zito A, Carbonara S, Ricci $\mathrm{G}$, et al. The role of omega-3 polyunsaturated fatty acids supplementation in childhood: A review. Recent Pat Cardiovasc Drug Discov 2013;8(1):42-55.

15. Marazzi G, Cacciotti L, Pelliccia F, Iaia L, Volterrani M, Caminiti G, et al. Long-term effects of nutraceuticals (berberine, red yeast rice, policosanol) in elderly hypercholesterolemic patients. Adv Ther 2011;28(12):1105-13

16. Sirtori CR, Galli C, Anderson JW, Arnoldi A. Nutritional and nutraceutical approaches to dyslipidemia and atherosclerosis prevention: Focus on dietary proteins. Atherosclerosis 2009;203(1):8-17.

17. Chen $\mathrm{CH}$, Yang JC, Uang YS, Lin CJ. Improved dissolution rate and oral bioavailability of lovastatin in red yeast rice products. Int J Pharm 2013;444(1-2):18-24.

18. Li Y, Guo C, Yang J, Wei J, Xu J, Cheng S. Evaluation of antioxidant properties of pomegranate peel extract in comparison with pomegranate pulp extract. Food Chem 2006;96(2):254-60.

19. Kelsey NA, Wilkins HM, Linseman DA. Nutraceutical antioxidants as novel neuroprotective agents. Molecules 2010;15(11):7792-814.

20. Augustin MA, Sanguansri L, Lockett T. Nano- and micro-encapsulated systems for enhancing the delivery of resveratrol. Ann N Y Acad Sci 2013;1290:107-12.

21. Vastano BC, Chen Y, Zhu N, Ho CT, Zhou Z, Rosen RT. Isolation and identification of stilbenes in two varieties of Polygonum cuspidatum. J Agric Food Chem 2000;48(2):253-6.

22. Cho IJ, Ahn JY, Kim S, Choi MS, Ha TY. Resveratrol attenuates the expression of HMG-CoA reductase mRNA in hamsters. Biochem Biophys Res Commun 2008;367(1):190-4.

23. Berrougui H, Grenier G, Loued S, Drouin G, Khalil A. A new insight into resveratrol as an atheroprotective compound: Inhibition of lipid peroxidation and enhancement of cholesterol efflux. Atherosclerosis 2009;207(2):420-7.

24. Mader I, Wabitsch M, Debatin KM, Fischer-Posovszky P, Fulda S. Identification of a novel proapoptotic function of resveratrol in fat cells: SIRT1-independent sensitization to TRAIL-induced apoptosis. FASEB J 2010;24(6):1997-2009.

25. Chen Q, Wang E, Ma L, Zhai P. Dietary resveratrol increases the expression of hepatic 7a-hydroxylase and ameliorates hypercholesterolemia in high-fat fed C57BL/6J mice. Lipids Health Dis 2012;11:56.

26. Spanier G, Xu H, Xia N, Tobias S, Deng S, Wojnowski L, et al. Resveratrol reduces endothelial oxidative stress by modulating the gene 
expression of superoxide dismutase 1 (SOD1), glutathione peroxidase 1 (GPx1) and NADPH oxidase subunit (Nox4). J Physiol Pharmacol 2009;60 Suppl 4:111-6.

27. Szewczuk LM, Penning TM. Mechanism-based inactivation of COX-1 by red wine m-hydroquinones: A structure-activity relationship study. J Nat Prod 2004;67(11):1777-82.

28. Frémont L. Biological effects of resveratrol. Life Sci 2000;66(8):663-73.

29. Shen MY, Hsiao G, Liu CL, Fong TH, Lin KH, Chou DS, et al. Inhibitory mechanisms of resveratrol in platelet activation: Pivotal roles of p38 MAPK and NO/cyclic GMP. Br J Haematol 2007;139(3):475-85.

30. Houston $\mathrm{M}$. The role of nutraceutical supplements in the treatment of dyslipidemia. J Clin Hypertens (Greenwich) 2012;14(2):121-32.

31. Patel KR, Scott E, Brown VA, Gescher AJ, Steward WP, Brown K Clinical trials of resveratrol. Ann N Y Acad Sci 2011;1215:161-9.

32. Miksicek RJ. Estrogenic flavonoids: Structural requirements for biological activity. Proc Soc Exp Biol Med 1995;208(1):44-50.

33. Nijjar PS, Burke FM, Bloesch A, Rader DJ. Role of dietary supplements in lowering low-density lipoprotein cholesterol: A review. J Clin Lipidol 2010;4(4):248-58.

34. Baum JA, Teng H, Erdman JW Jr, Weigel RM, Klein BP, Persky VW, et al. Long-term intake of soy protein improves blood lipid profiles and increases mononuclear cell low-density-lipoprotein receptor messenger RNA in hypercholesterolemic, postmenopausal women. Am J Clin Nutr 1998;68(3):545-51.

35. Harland JI, Haffner TA. Systematic review, meta-analysis and regression of randomised controlled trials reporting an association between an intake of circa $25 \mathrm{~g}$ soya protein per day and blood cholesterol. Atherosclerosis 2008;200(1):13-27.

36. Reynolds K, Chin A, Lees KA, Nguyen A, Bujnowski D, He J. A meta-analysis of the effect of soy protein supplementation on serum lipids. Am J Cardiol 2006;98(5):633-40.

37. Anderson JW, Johnstone BM, Cook-Newell ME. Meta-analysis of the effects of soy protein intake on serum lipids. N Engl J Med 1995;333(5):276-82.

38. Food labeling: Health claims; Soy protein and coronary heart disease. Food and Drug Administration, HHS. Final rule. Fed Regist 1999;64(206):57700-33.

39. Lovati MR, Manzoni C, Corsini A, Granata A, Frattini R, Fumagalli R, et al. Low density lipoprotein receptor activity is modulated by soybean globulins in cell culture. J Nutr 1992;122(10):1971-8.

40. Lovati MR, Manzoni C, Corsini A, Granata A, Fumagalli R, Sirtori CR $7 \mathrm{~S}$ globulin from soybean is metabolized in human cell cultures by a specific uptake and degradation system. J Nutr 1996;126(11):2831-42.

41. Mozaffarian D, Rimm EB. Fish intake, contaminants, and human health Evaluating the risks and the benefits. JAMA 2006;296(15):1885-99.

42. Calder PC. n-3 Fatty acids and cardiovascular disease: Evidence explained and mechanisms explored. Clin Sci (Lond) 2004;107(1):1-11.

43. Schmidt S, Willers J, Stahl F, Mutz KO, Scheper T, Hahn A, et al. Regulation of lipid metabolism-related gene expression in whole blood cells of normo- and dyslipidemic men after fish oil supplementation. Lipids Health Dis 2012;11:172.

44. Dietary supplementation with n-3 polyunsaturated fatty acids and vitamin E after myocardial infarction: Results of the GISSI - Prevenzione trial Gruppo Italiano per lo Studio della Sopravvivenza nell' Infarto miocardico. Lancet 1999;354(9177):447-55

45. Houston MC, Fazio S, Chilton FH, Wise DE, Jones KB, Barringer TA, et al. Nonpharmacologic treatment of dyslipidemia. Prog Cardiovasc Dis 2009;52(2):61-94

46. American Heart Association Nutrition Committee, Lichtenstein $\mathrm{AH}$, Appel LJ, Brands M, Carnethon M, Daniels S, et al. Diet and lifestyle recommendations revision 2006: A scientific statement from the American Heart Association Nutrition Committee. Circulation
2006;114(1):82-96

47. Needleman P, Raz A, Minkes MS, Ferrendelli JA, Sprecher H. Triene prostaglandins: Prostacyclin and thromboxane biosynthesis and unique biological properties. Proc Natl Acad Sci U S A 1979;76(2):944-8.

48. Zeng L, An S, Goetzl EJ. EP4/EP2 receptor-specific prostaglandin E2 regulation of interleukin- 6 generation by human HSB. 2 early T cells. J Pharmacol Exp Ther 1998;286(3):1420-6.

49. Lau CW, Yao XQ, Chen ZY, Ko WH, Huang Y. Cardiovascular actions of berberine. Cardiovasc Drug Rev 2001;19(3):234-44.

50. Kong W, Wei J, Abidi P, Lin M, Inaba S, Li C, et al. Berberine is a novel cholesterol-lowering drug working through a unique mechanism distinct from statins. Nat Med 2004;10(12):1344-51.

51. Cicero AF, Ertek S. Metabolic and cardiovascular effects of berberine: From preclinical evidences to clinical trial results. Clin Lipido 2009;4(5):553-63.

52. Brusq JM, Ancellin N, Grondin P, Guillard R, Martin S, Saintillan Y, et al. Inhibition of lipid synthesis through activation of AMP kinase: An additional mechanism for the hypolipidemic effects of berberine. J Lipid Res 2006;47(6):1281-8.

53. Dong H, Zhao Y, Zhao L, Lu F. The effects of berberine on blood lipids A systemic review and meta-analysis of randomized controlled trials. Planta Med 2013;79(6):437-46.

54. Derosa G, Maffioli P, Cicero AF. Berberine on metabolic and cardiovascular risk factors: An analysis from preclinical evidences to clinical trials. Expert Opin Biol Ther 2012;12(8):1113-24.

55. Ma J, Li Y, Ye Q, Li J, Hua Y, Ju D, et al. Constituents of red yeas rice, a traditional Chinese food and medicine. J Agric Food Chem 2000;48(11):5220-5.

56. Went FA. Monascus purpureus fungus angquac the new thelobolee Ann Soc Nat Bot 1895;8:1-17

57. Endo A, Monacolin K. A new hypocholesterolemic agent produced by a Monascus species. J Antibiot (Tokyo) 1979;32(8):852-4.

58. Journoud M, Jones PJ. Red yeast rice: A new hypolipidemic drug. Life Sci 2004;74(22):2675-83

59. Lin CC, Li TC, Lai MM. Efficacy and safety of Monascus purpureus went rice in subjects with hyperlipidemia. Eur $\mathrm{J}$ Endocrinol 2005;153(5):679-86.

60. Becker DJ, Gordon RY, Halbert SC, French B, Morris PB, Rader DJ Red yeast rice for dyslipidemia in statin-intolerant patients: A randomized trial. Ann Intern Med 2009;150(12):830-9, W147-9.

61. Halbert SC, French B, Gordon RY, Farrar JT, Schmitz K, Morris PB, et al. Tolerability of red yeast rice $(2,400 \mathrm{mg}$ twice daily) versus pravastatin (20 mg twice daily) in patients with previous statin intolerance. Am J Cardiol 2010;105(2):198-204.

62. Available from: http://www.fda.gov/OHRMS/DOCKETS/dailys/01/ Jun01/061101/let0494.pdf.

63. Olszanecki R, Jawien J, Gajda M, Mateuszuk L, Gebska A Korabiowska M, et al. Effect of curcumin on atherosclerosis in apoE/ LDLR-double knockout mice. J Physiol Pharmacol 2005;56(4):627-35.

64. Peschel D, Koerting R, Nass N. Curcumin induces changes in expression of genes involved in cholesterol homeostasis. J Nutr Biochem 2007;18(2):113-9.

65. Soni KB, Kuttan R. Effect of oral curcumin administration on serum peroxides and cholesterol levels in human volunteers. Indian J Physiol Pharmacol 1992;36(4):273-5

66. El Sohaimy SA. Functional foods and nutraceuticals-modern approach to food science. World Appl Sci J 2012;20(5):691-708

67. Available from: http://www.researchandmarkets.com/reports/3600554/ nutraceuticals-market-functional-food-dietry.

68. Available from: http://www.naturalproductsinsider.com articles/2014/05/indian-nutraceutical-market-is-filled-with-promis. aspx/. 